\title{
Studies on Thermal and Morphological Behavior of 3- Aminopropyltriethoxysilane Grafted Epoxidized Ethylene- Propylene-Diene Terpolymer
}

\author{
M.Vadivel ${ }^{1}$, M. Suresh Chandra Kumar ${ }^{1, *}$, V.Selvam ${ }^{1}$, M. Alagar ${ }^{2}$ \\ ${ }^{1}$ Polymer Nanocomposite Centre, Department of Chemistry, Scott Christian College, Nagercoil 629 003, India \\ ${ }^{2}$ Department of Chemical Engineering, Anna University, Chennai 600 025, India
}

\begin{abstract}
A novel and new copolymer of 3-aminopropyltriethoxysilane (APTES) on epoxided ethylenepropylene-diene terpolymer (eEPDM) via Sol-Gel Process. EPDM was epoxidized with an in situ formed per formic acid to prepare epoxided EPDM (eEPDM).The effect of eEPDM concentration, APTES concentration, reaction time and reaction temperature on the graft co polymerization was studied. The grafting efficiency of APTES on eEPDM, eEPDM was confirmed by Fourier Transform infrared (FT-IR) spectroscopy. The Thermal behaviors of EPDM, eEPDM, g-EPDM were studied by Thermo gravimetric analysis and DSC. The Morphological properties of Epoxidation of EPDM and eEPDM-g-APTES are compared.
\end{abstract}

Keywords: eEPDM, eEPDM-g-APTES, Grafting, process, sol-gel

\section{INTRODUCTION}

It has been reported that ethylene-propylene- diene terpolymer (EPDM) has good resistances to heat, light, oxygen and ozone, because it has low contents of the nonconjugated diene component (1-4). Epoxidation is the simple and efficient method for introducing a new reactive group into polyolefins, leading to new and useful properties and wide use in a variety of applications (5). Epoxidation of olefinic compounds using organic peracids has been extensively studied since oxiranes were prepared by reacting ethylenic compounds with perbenzoic acid. Oxiranes are generally prepared using perbenzoic acid (9), chloroperbenzoic acid (10) and monoperphthalic acid (11). Performic acid is an extremely active organic peracid (12-16) used for the epoxidation, but, owing to its instability (17), it has to be prepared in situ.

The development of grafted hybrid polymeric materials yields new materials with the balance of properties for high performance applications (18-22). The grafting of silane onto ethylene-propylenediene terpolymer (EPDM) is a novel technique used for the commercial production of cross linked EPDM for cable insulation (23). Tanida and Sato prepared heat shrinkable tubes by grafting VTMO with EPDM (24). Kawada et al. synthesized silica filled silane grafted EPDM and EPDM composites (25) and found that the heat resistance of silane grafted EPDM was considerably higher than that of ungrafted EPDM. Umeda et al. investigated the thermal stability of silane grafted EPDM and EPDM (26) and they concluded that the silane grafted EPDM exhibits better thermal stability than those of ungrafted EPDM.

In the present study, a novel and new graft copolymer of 3-aminopropyltriethoxysilane onto epoxidized ethylene-propylene-diene terpolymer (eEPDM-g- APTES) has been synthesized in toluene. The effect of eEPDM concentration, APTES concentration, reaction time and reaction temperature on the graft co polymerization was studied. The grafting mechanism of APTES onto eEPDM was confirmed by FT- IR spectroscopy. The mechanical, morphological and thermal properties of eEPDM and eEPDM-g-APTES are compared.

\subsection{Materials}

\section{EXPERIMENTAL}

The EPDM (ENB) elastomer used in this study was a commercial grade Nordel IP 4770P (ethylene/propylene/ 5-ethylidene-2-norbornene $=70 / 25 / 5$ by wt. $\%$, Mooney viscosity, $\mathrm{ML}_{(1+4)}$ at $125^{\circ} \mathrm{C}$ is 70 and density of $0.87 \mathrm{~g} / \mathrm{cc}$ ) of DuPont Dow elastomers, USA. 3-aminopropyltriethoxysilane (APTES), $\left(\mathrm{M}_{\mathrm{w}}=\right.$ 221.3, boiling point $=217^{\circ} \mathrm{C}$, density $=0.946 \mathrm{~g} \cdot \mathrm{cm}^{-3}$, ) was procured from Aldrich Chemicals, USA. Dibutyltindilaurate $\left(\right.$ DBTDL) $\left(\right.$ density $=1.066 \mathrm{~g} . \mathrm{cm}^{3}$, freezing point $>110{ }^{\circ} \mathrm{C}, \mathrm{Mw}=631.56$ ) was purchased from Merck, Germany. Analytical grade formic acid (88\%), hydrogen peroxide (30\%), toluene,n-hexane were used as received.

\subsection{In situ epoxidation of ethylene-propylene-diene terpolymer}

The EPDM was first dissolved in toluene in a three necked flask equipped with a mechanical stirrer and thermometer, and maintained at $50^{\circ} \mathrm{C}$ in a water bath. Under continuous stirring, the EPDM solution was 
acidified stepwise with $88 \%$ formic acid to $\mathrm{pH} 2-3$. The epoxidation was performed by dropping the required amount of $\mathrm{H}_{2} \mathrm{O}_{2}(30 \%)$ for 30 min. A rapid introduction of this reagent is not recommended, because it causes excessive development of oxygen due to the decomposition of hydrogen peroxide at high temperature. The reaction was continued for $7 \mathrm{~h}$ at $50^{\circ} \mathrm{C}$. After epoxidation, the rubber was coagulated in acetone, thoroughly washed with distilled water, soaked in $1 \%$ w $/ \mathrm{v} \mathrm{Na}_{2} \mathrm{CO}_{3}$ solution for $24 \mathrm{~h}$, and finally rinsed with distilled water. The rubber prepared was dried in a vacuum oven at $40^{\circ} \mathrm{C}$ to a constant weight.

\subsection{Preparation of eEPDM-g-APTES}

The grafting reactions were carried out in $500 \mathrm{ml}$ three necked round bottom flask equipped with a reflux condenser, a Teflon-coated magnetic stirring bar and a nitrogen inlet. A given amount of eEPDM was dissolved in $200 \mathrm{ml}$ toluene in the flask. APTES at a given mole ratio was dissolved in $50 \mathrm{ml}$ of toluene and then added with dibutyltindilaurate $(1 \%)$. The reaction was carried out under various experimental conditions (Table 1). After the completion of reaction, the products were precipitated with methanol, filtered and dried in vacuum.

\subsection{Isolation of graft terpolymer}

In the synthesis, the products obtained consists of ungrafted eEPDM, poly(aminopropyltriethoxysilane) and eEPDM-g-APTES. The ungrafted eEPDM was separated from rest of the products by extraction using nhexane. The 3-aminopropyltriethoxysilane grafted eEPDM (eEPDM-g- APTES) was separated from poly(aminopropyltriethoxysilane) using DMF where the former is soluble and latter is insoluble.

The total conversion (\%) was calculated from the ratio of the total weight of products formed to the weight of eEPDM charged. The grafting ratio and grafting efficiency were determined on the basis of changes in polymer weight during the reaction process and the total amount of eEPDM-g-APTES formed respectively. The grafting ratio and grafting efficiency were calculated from the following equations:

Total conversion $(\%)=$

Grafting ratio $(\%) \quad=$

Grafting efficiency $(\%)=$
Total weight of polymers formed

\begin{tabular}{ll}
\hline Weight of eEPDM charged & $\times 100$ \\
$\frac{\text { Weight of eEPDM-g-APTES }}{\text { Weight of eEPDM charged }} \times 100$ \\
Weight of eEPDM-g-APTES
\end{tabular}

Total weight of polymers formed

\subsection{Measurements}

EPDM, eEPDM and eEPDM-g-APTES were characterized with the help of IR spectra obtained from Shimadzu-1800S, using solvent casted thin films. The tensile tests were carried out using a universal testing machine (ZWICK-1484) at $27{ }^{\circ} \mathrm{C}$ with a cross head speed was $500 \mathrm{~mm} / \mathrm{min}$. using dumbell shaped tensile specimens according to ASTM D 412-87. The hardness of the samples was measured according to ASTM D 2240-86. The DSC was performed on a NETZSCH DSC 200 thermal analyzer under nitrogen flow in the temperature range -100 to $400{ }^{\circ} \mathrm{C}$, with a heating rate of $10{ }^{\circ} \mathrm{C} / \mathrm{min}$. Thermo gravimetric analysis (TGA) were carried using a NETZSCA TG 209 instrument under nitrogen atmosphere at a heating rate of $10{ }^{\circ} \mathrm{C} / \mathrm{min}$. A Quanta-200, FEG, scanning electron microscope was employed to examine the morphology of the gold coated surfaces of cryogenically fractured samples.

\section{RESULTS AND DISCUSSION}

The tentative grafting reaction mechanism of APTES onto eEPDM is presented in Scheme 1.

The grafting mechanism proceeds via aminolysis reaction where the eEPDM (ENB) polymeric chain covalently bonds with the silane after sol-gel processing. 

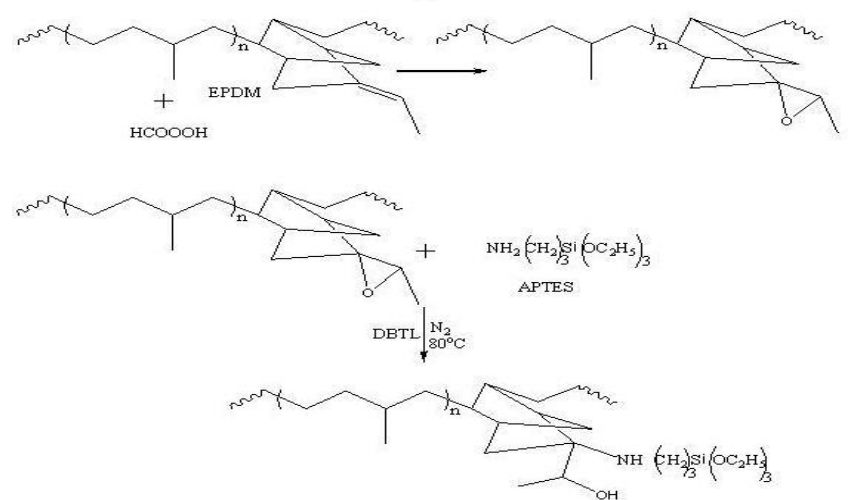

Scheme 1 Schematic representation of grafting between eEPDM and APTES

\subsection{Fourier-transform infrared spectroscopy}

Fig. 1 shows the FTIR spectra of EPDM, eEPDM and eEPDM-g-APTES. The IR spectra of EPDM (Fig. 1(a)) shows the $\mathrm{C}-\mathrm{H}$ stretching vibration (aliphatic) at $2911 \mathrm{~cm}^{-1},-\mathrm{CH}_{2}$ rocking vibration at $1451 \mathrm{~cm}^{-1}$, $\mathrm{CH}_{3}$ symmetric bending vibration at $1367 \mathrm{~cm}^{-1}$ due to the presence of propylene group, $-\left(\mathrm{CH}_{2}\right)_{\mathrm{n}}-$ wagging vibration at $721 \mathrm{~cm}^{-1}$ due to the presence of polyethylene chain, $\mathrm{C}-\mathrm{C}$ stretching vibration at $2851 \mathrm{~cm}^{-1}$, and the unsaturation band $(>\mathrm{C}=\mathrm{CH}-)$ at $811 \mathrm{~cm}^{-1}$ due to the presence of ENB content. The FTIR spectra of eEPDM (Fig. 1(b)) was characterized by the presence of a epoxide band at $870 \mathrm{~cm}^{-1}$ due to asymmetric epoxide ring stretching. Furthermore, the intensity of the $>\mathrm{C}=\mathrm{CH}-$ band at $811 \mathrm{~cm}^{-1}$ decreases because of the epoxidation of EPDM, which demonstrates that the $\mathrm{C}=\mathrm{C}$ double bond in $\mathrm{EPDM}$ was converted to the epoxy functional group in eEPDM. The conversion of double bonds to epoxide was obtained as $50 \%$ (ca.2.4 mol \%). To take advantage of relative change of absorbance at 811 and $870 \mathrm{~cm}^{-1}$, a quantitative analysis was performed by area measurement of methyl deformation band at $1369 \mathrm{~cm}^{-1}$ as internal standard (22). Fig. 1(c) illustrates the IR spectra of eEPDM-g-APTES which reveals: O-H stretching vibration at $3250 \mathrm{~cm}^{-1}, \mathrm{C}-\mathrm{H}$ stretching vibration at $2900 \mathrm{~cm}^{-1}$ and $\mathrm{C}-\mathrm{H}$ deformation at $1443 \mathrm{~cm}^{-1}$. The disappearance of the absorption band at $870 \mathrm{~cm}^{-1}$ clearly indicates that the reaction at the epoxide groups has proceeded. A new band has been formed at $1080 \mathrm{~cm}^{-1}$ that is characteristic of Si-O bonds derived from APTES.

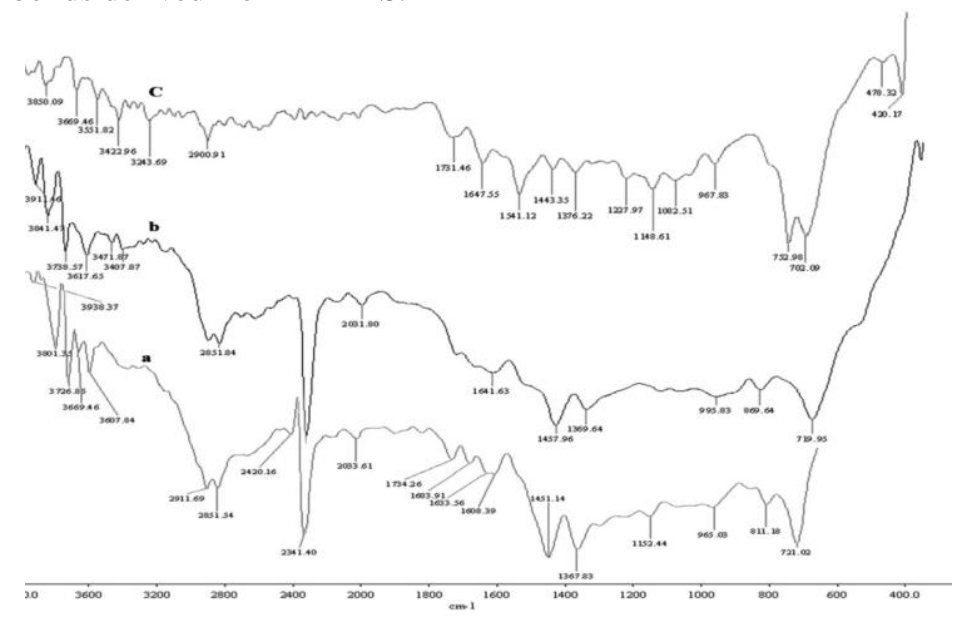

Fig. 1 FTIR spectra of (a) EPDM (b) eEPDM and (c) eEPDM-g-APTES

\subsection{Effect of reaction conditions on graft copolymerization}

\subsubsection{Effect of eEPDM content}

The effect of eEPDM content on the graft copolymerization is presented in Fig. 2. The grafting reaction was carried out at $80^{\circ} \mathrm{C}$ for $4 \mathrm{~h}$ with $2.5 \mathrm{wt} . \%$ of APTES. The grafting efficiency increase linearly with increase in concentration of eEPDM, due to the availability of epoxy ring present in eEPDM. The grafting efficiency for $10 \mathrm{wt} . \%$ eEPDM is $20 \%$ and that of $30 \mathrm{wt} . \%$ is $30 \%$. With higher concentrations of eEPDM, more active centers are generated in the system and thus the grafting efficiency increases. On the other hand, at lower concentrations of eEPDM, the fewer the active centers, and thus higher degree of homopolymerization of APTES. 


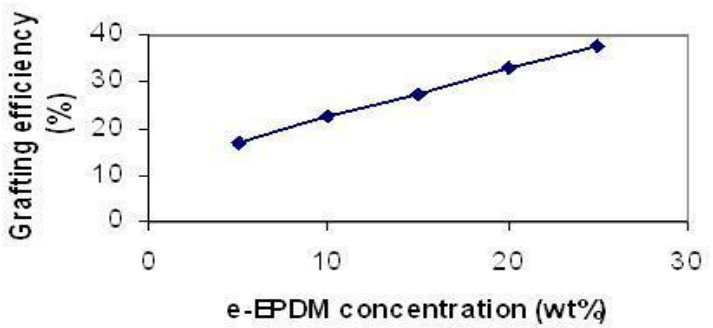

Fig.2. Plot of grafting efficiency against eEPDM concentration (APTES, $2.5 \mathrm{wt} \%$; reaction temperature, $80^{\circ} \mathrm{C}$; reaction time, $4 \mathrm{~h}$ ).

\subsubsection{Effect of APTES concentration}

Fig. 3 shows the effect of APTES concentration on the grafting efficiency. The grafting reactions were carried out at $80^{\circ} \mathrm{C}$ for $4 \mathrm{~h}$ with $1,1.5,2,2.5$ and $3 \mathrm{wt} . \%$ of APTES onto eEPDM. The grafting efficiency increases with increase in APTES concentration and attains the maximum and then declines down. The grafting efficiency for 2 wt.\% of APTES is 23.83 whereas the highest grafting efficiency of 25.01 is observed for $2.5 \mathrm{wt} \%$ of APTES. But, when the grafting was carried out using $3 \mathrm{wt} \%$ APTES, the grafting efficiency decreases to $20 \%$. The dramatic decline of grafting efficiency at higher concentration of APTES is due to the formation of homopolymer. These homopolymer successfully hinder the rate of penetration of APTES molecules to eEPDM macro radicals, resulting in decrease in grafting efficiency.

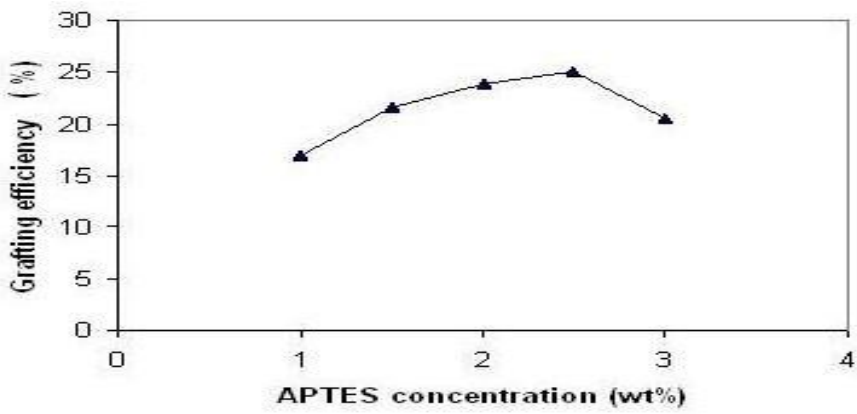

Fig.3. Plot of grafting efficiency against APTES concentration (reaction temperature, $80^{\circ} \mathrm{C}$; reaction time, $4 \mathrm{~h}$ ).

\subsubsection{Effect of reaction time}

The efficiency of grafting of APTES onto eEPDM with respect to reaction time, is given in Fig. 4. The reactions were carried out at $80^{\circ} \mathrm{C}$ with $0.1 \mathrm{wt} . \%$ of DBTL for $2,4,6,8$ and $10 \mathrm{~h}$. It is observed that the grafting efficiency increases with increase in reaction time upto $4 \mathrm{~h}$, and beyond $4 \mathrm{~h}$ there was no appreciable effect observed on the grafting efficiency. However, the total conversion increases with increase in reaction time due to the formation of the homopolymer.

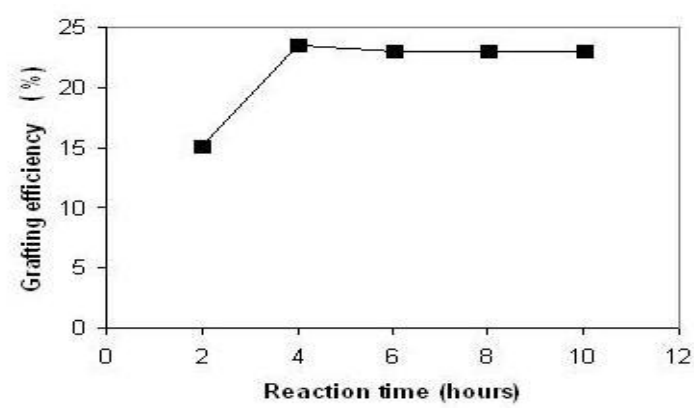

Fig.4. Plot of grafting efficiency against reaction time ((APTES, $2.5 \mathrm{wt} \%$; reaction temperature, $\left.80^{\circ} \mathrm{C}\right)$.

\subsubsection{Effect of reaction temperature}

The influence of temperature on the grafting is presented in Fig. 5. The reaction was carried out with $2.5 \mathrm{wt} . \%$ of APTES and $0.1 \mathrm{wt} . \%$ of DBTL at different temperatures, namely, $40,50,60,70$ and $80^{\circ} \mathrm{C}$. The grafting efficiency increases with increasing reaction temperature from 40 to $80^{\circ} \mathrm{C}$ due to increase in the rate of decomposition of epoxidation group. However beyond $80^{\circ} \mathrm{C}$ there was no appreciable change in the grafting efficiency observed, which indicates the completion of the reaction. 


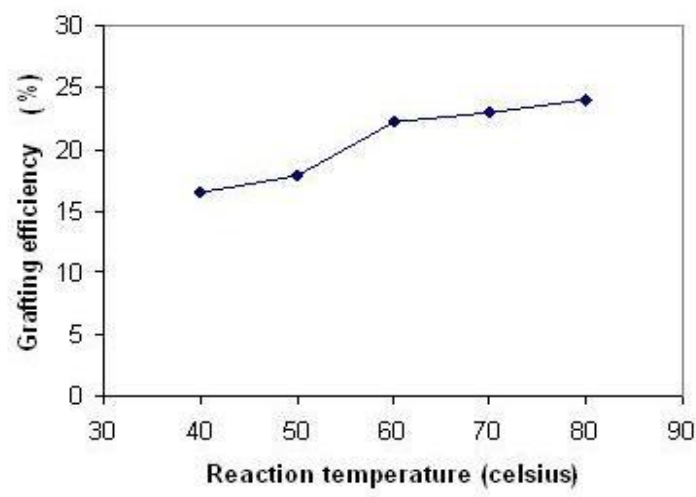

Fig.5. Plot of grafting efficiency against reaction temperature ((APTES, $2.5 \mathrm{wt} \%$; reaction time, $4 \mathrm{~h}$ ).

Table 1 Conditions of graft copolymerization

\begin{tabular}{|l|c|l|l|l|l|}
\hline Condition & \multicolumn{5}{|c|}{ Description } \\
\hline eEPDM Concentration & 5 & 10 & 15 & 20 & 25 \\
\hline APTES Concentration & 1 & 1.5 & 2 & 2.5 & 3 \\
\hline Reaction time (h) & 2 & 4 & 6 & 8 & \\
\hline $\begin{array}{l}\text { Reaction temperature } \\
\left({ }^{\mathrm{O}} \mathrm{C}\right)\end{array}$ & 50 & 60 & 70 & 80 & \\
\hline
\end{tabular}

\subsection{Thermal properties}

The effect of APTES grafting on thermal properties was determined by thermo gravimetric analyzer. Thermograms of EPDM, eEPDM and eEPDM-g- APTES are given in Fig. 6. The inception decomposition temperature of EPDM, eEPDM and eEPDM g- APTES are 440, 444 and $449^{\circ} \mathrm{C}$ respectively. Similarly the final decomposition temperatures of EPDM, eEPDM and eEPDM -g- APTES are 482,486 and $490{ }^{\circ} \mathrm{C}$ respectively. The higher thermal stability of eEPDM compared to EPDM can be explained by the substitution of the double bond on the EPDM side chain with the epoxy rings (25). The grafting of APTES onto eEPDM also increases both inception and final decomposition temperatures because of the inherent high heat resistances of EPDM and APTES (26).

The glass transition behaviour of the hybrid material is associated with cooperative motion of large chain segment. The DSC results of EPDM, eEPDM and eEPDM g- APTES are shown in Fig. 7. The midpoints of the transition temperature curve in the DSC curve are recorded as Tg values. The Tg values EPDM, eEPDM and eEPDM-g-APTES are $-43,-40$ and $-36{ }^{\circ} \mathrm{C}$. The glass transition temperatures $\mathrm{Tg}$, increased due epoxidation. The increase in $\mathrm{Tg}$ as a result of epoxidation may be caused by the presence of the polar epoxide group, which gives more rigid backbone than the unsaturated group $(27,28)$. The results also indicate that the $\mathrm{Tg}$ value for eEPDM-g-APTES is higher than EEPDM and EPDM, due to the silane content. Similar behaviour was obtained for PMMA-MSMA hybrid system (29)

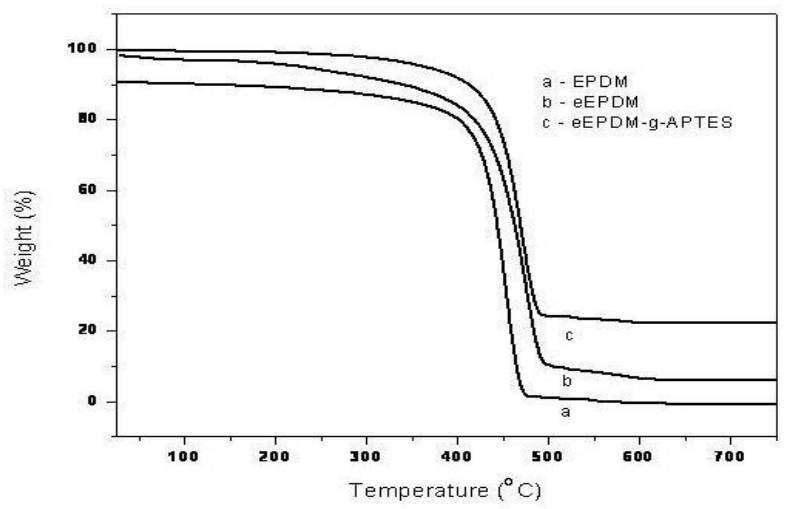

Fig. 6. TGA curves of (a) EPDM (b) eEPDM (c) eEPDM-g-APTES 


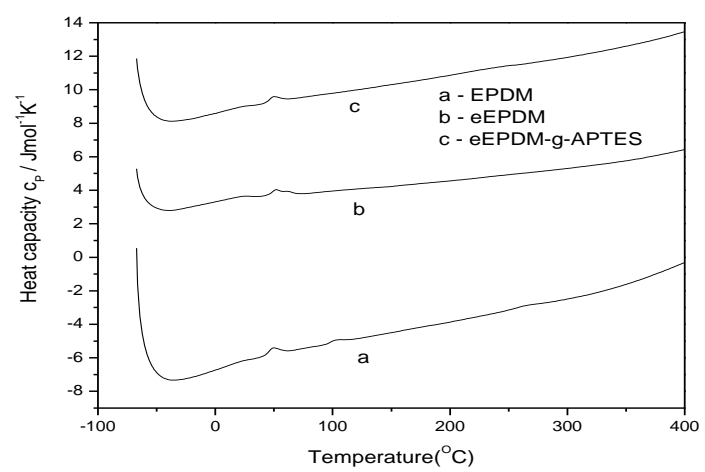

Fig. 7. DSC curves of (a) EPDM (b) eEPDM (c) eEPDM-g-APTES

\subsection{SEM Analysis}

The morphological characterization of the films was carried out through SEM analysis. Fig. 8 and 9 shows the SEM photographs of EPDM and EEPDM which indicates a plane and smooth surface with some bigger particles. However, the surface of eEPDM-g-APTES is smoother with some orientations as seen in Fig. 10. The orientation appears on the surface of eEPDM-g-APTES can be probably due to chemical bonding between APTES and eEPDM chains.

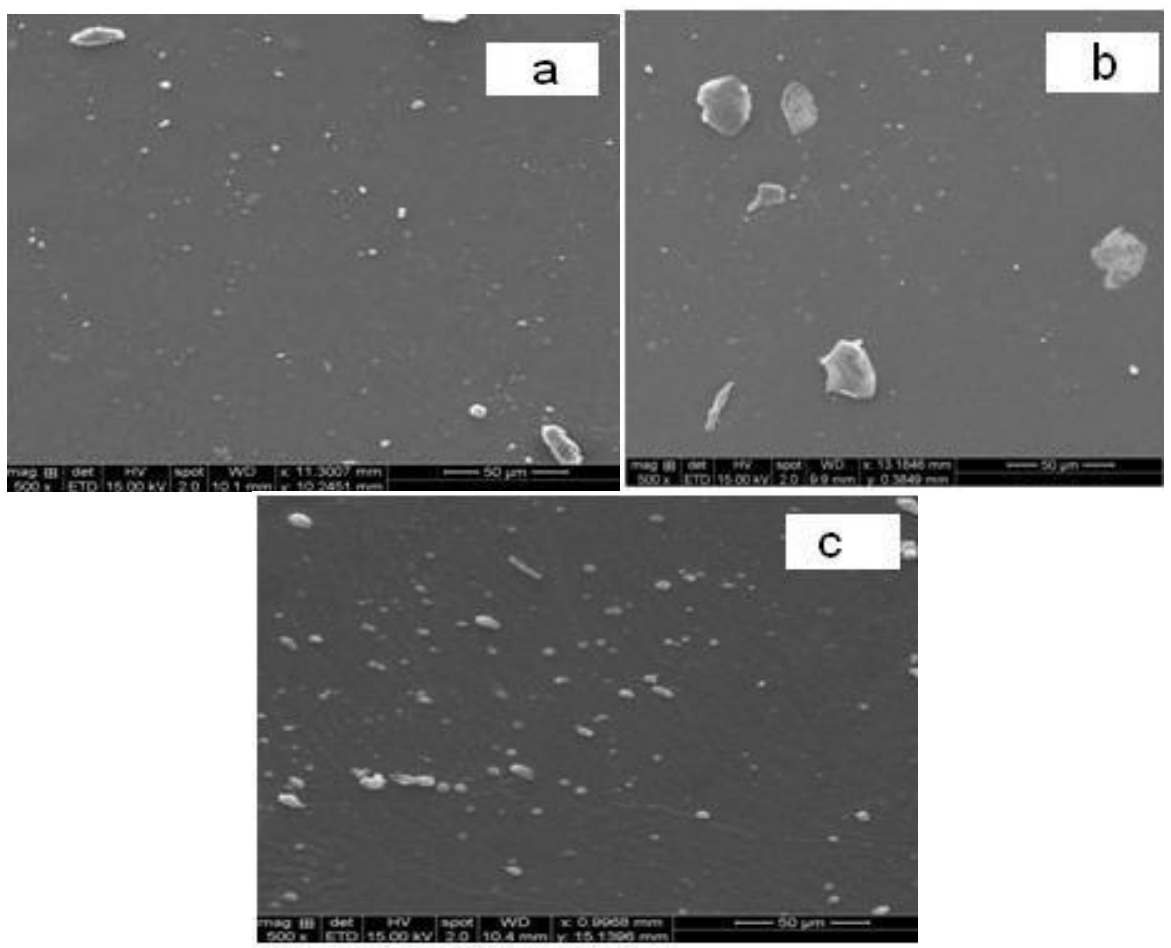

Fig. 8. SEM photographs of (a) EPDM (b) eEPDM (c) eEPDM-g-APTES

\section{CONCLUSION}

EEPDM-g-APTES graft copolymer was synthesized in toluene. The following conclusions are made based on the data resulted from different experimental studies. The grafting of APTES onto eEPDM proceeds via aminolysis reaction where the eEPDM polymeric chain covalently bonds with the silane which has been confirmed from FTIR spectra. It was ascertained that the threshold grafting efficiency was maximum at $2.5 \mathrm{wt}$. $\%$ of APTES. The grafting efficiency increases with increase of temperature and eEPDM content. The epoxidation of EPDM as well as grafting of APTES onto eEPDM improve thermal characteristics. 


\section{REFERENCES}

[1] Anil Kumar, P. V., Anil Kumar, S.,Varughese, K.T., and Thomas, S. (2012) J. Mater. Sci. 47, 3293-3304.

[2] Yuken, C., Chuanhui, X., Liming, C., Yanpeng, W., and Xiaodong, C. (2012) Polymer Testing. 31, $728-736$.

[3] Dubey, K. A., Bhardwaj, Y. K., Raj Kumar, K., Panicker, L., Chaudhari, C.V., Chakraborty, S.K., and Sabharwal, S. (2012) J. Polym. Res. 19, 9876-9885.

[4] Zhenhua, W., Yonglai, L, Jun, L., Zeimen, D., Liqun, Z., and Weimin, W. (2011) J. AppL Polym.Sci. 119, $1144-1155$.

[5] Mahapatra, S. P., Tripathy, D. K., and Lee, Y. (2012) Polym.Bull. 68, 1965-1976.

[6] Bhattacharjee, S., and Anderson, J. A. (2006) J. Mol. Catal. A Chem. 249, 103-110.

[7] Samantaray, S. K., and Parida, K. (2005) Catal.Commun. 6, 578-581.

[8] Ziolek, M. (2004) Catal.Today. 90, 145-150.

[9] Grigoropoulou, G., Clark, J.H., and Elings, J.A. (2003) Green Chem. 5, 1-7.

[10] Sanderson, W. R. (2000) Pure Appl. Chem. 72, 1289-1304.

[11] Hiyoshi, N. (2012) Applied Catalysis A. 420, 164-169.

[12] Shen, X., Fan, W., He, Y., Wu, P., Wang, J., and Tatsumi, T. (2011) Applied Catalysis A. 401, 37-45.

[13] Bera, R., and Koner, S. (2012) Inorganica Chemica Acta. 384, 233-238.

[14] Azizi, H., Morshedian, M., Barrikani, M., and Wagner, M.H. (2011) Advances in Polymer Technology. 30,4, 286-300.

[15] Kim, K.J. (2010) J. AppL Polym.Sci. 116, 237-244.

[16] Bailey, M., and Kontoulou, M. (2011) Polymer. 50, 2472-2480.

[17] Deflorian, F., Rossi, S., Fedal, M., and Motte, C. (2010) Progress in Organic Coating. 69, 158-166.

[18] Zhang, C., Zhang, Z. X., Pal, K., Shin, O. G., Choel Jo, H., Lee, S. H., and Kim, J. K. (2011) J. Macromolecular. Sci.Part B. 50, 2, 291-299.

[19] Alagar, M., Abdul majeed, S. M., Selvaganabathi, A., and Gnanasundram, P. (2006) European Polymer Jounal. 42, $2,336-347$.

[20] Ramar, P., and Alagar, M. (2009) J. AppL Polym.Sci. 111, 2859-2871.

[21] Umeda, I., Takemura, Y., Watanable, J., Funahashi Y. (1998) Japanese pat. 6372745.

[22] Ng, S.C., Gan, L.H. (1981) Eur. Polym. J 17, 1073-1077.

[23] McCable, R.H. (1964) Rubber Age 96, 396.

[24] Ramar, P., Alagar, M. (2004) Polym. Adv. Technol. 15, 377-381.

[25] Roland, C.M.(1992) Macromolecules 25, 7031-7036.

[26] Roland, C.M., Kallitisis,K.J., Gravalos, K.G. (1993) Macromolecules 26, 6474-6476.

[27] Hung, Z.H., Qiu, Y. (1997) Polymer 38,3, 521-526. 